\title{
Sirenomelia: The Mermaid Syndrome-A Rare Case Report
}

\author{
*SF Siddiqua ${ }^{1}$, S Abbasi $^{2}$, AS Hasan ${ }^{3}$
}

\begin{abstract}
Sirenomelia, which is also known as mermaid syndrome, is an extremely rare congenital developmental disorder characterized by anomalies of the lower spine and the lower limbs. Affected infants are born with partial or complete fusion of the legs ${ }^{1}$. Additional malformations may also occur including genitourinary abnormalities, gastrointestinal abnormalities, anomalies of the lumbarsacral spine and pelvis and absence or underdevelopment (agenesis) of one or both kidneys. Affected infants may have one foot, no feet or both feet, which may be rotated externally. The tailbone is usually absent and the sacrum is partially or completely absent as well. Additional conditions may occur with sirenomelia including imperforate anus, spina bifida, and heart (cardiac) malformations. Sirenomelia is often fatal during the newborn period. The exact cause of sirenomelia is unknown, most cases occur randomly for no apparent reason (sporadically). We report a case of 30 years old primi wt $115 \mathrm{~kg}$, non diabetic, normotensive, euthyroid at 38 weeks pregnancy deliverd a baby with mermaid syndrome.
\end{abstract}

Key Words: Mermaid syndrome, siremonelia, pregnancy, obesity, Potters facies.

\section{Introduction}

In Greek mythology, the Sirens were three creatures with the head of a woman and the body of a bird from the wings down. Over time, these bird-women were portrayed as more aquatic creatures, and eventually with a full mermaid-like appearance ${ }^{1}$. Sirenomelia is a rare and fatal congenital defect characterized by varying degrees of lower limb fusion, thoracolumbar spinal anomalies, sacrococcygeal agenesis, genitourinary, and anorectal atresia, Woffian or Mullerian duct agenesis. Gonads are usually spared. Because of the resultant oligohydroamnios, these infants most often have Potter's facies and pulmonary hypoplasia. The rarity of the case is obvious from the fact that many a gynecologist might not have come across a case of sirenomelia in their whole professional carrier ${ }^{2}$. Sirenomelia "The Mermaid Syndrome" is found approximately 1:1,00000 live births and is fatal within the firstday of life because of complications of abnormal kidney, urinary system and anorectal development. It was first describe by Rocheus in 1542 and Palfyn in 1553. This syndrome has strong association (22\%) with maternal Diabetes mellitus and relative risk 1:200-250. Intake of haloperidol, cadmium, lead, vitaminA, vascular hypo perfusion may be causative factors ${ }^{3}$. We report a case of sirenomelia where maternal obesity may be the cause of this rare anomaly.

\section{Case Report}

A 30 years old primi wt $115 \mathrm{~kg}$, non diabetic, normotensive, euthyroid at 38 weeks of gestation admitted with labour pain. It was her spontaneous pregnancy and she was in regular antenatal checkup.

\footnotetext{
$1 *$ Prof. Sehereen Farhad Siddiqua, Professor and Head, Department of Obstetrics and Gynaecology, Anwer Khan Modern Medical College Hospital

${ }^{2}$ Dr. Sharmin Abbasi, Assistant Professor, Department of Obstetrics and Gynaecology, Anwer Khan Modern Medical College Hospital

${ }^{3}$ Dr. Abrar Saqif Hasan, Medical Officer, BIRDEM

*Corresponding Author

Date of submission: 24.03.2017, Date of acceptance: 07.04.2017
}

AKMMC J 2017; 8(2) : 144-147 


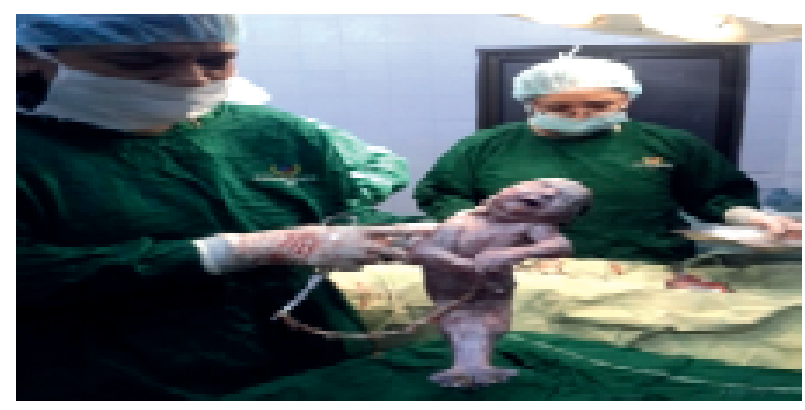

At 13 weeks her down's screening was normal. In 20 weeks anomaly scan done AFI was almost nil and the lower limbs did not visualized properly. Every 2-3 weeks interval we did USG but she remained anhydramnios throughout the pregnancy. Patient party was counseled that the baby may had multiple congenital anomaly and about the fate of the baby. They were advised for termination. But patient refused and pregnancy continued as per patients choice. There was no history of taking any teratogenic agents and no family history of congenital anomalies or still birth. She delivered a term baby with $2.6 \mathrm{~kg}$ with fused lower limbs. The baby cried immediately after birth. The apgar score was 4 at $1 \mathrm{~min}$ and 1 at $5 \mathrm{~min}$. After consultation with the parents baby kept under oxygen and they refused to take NICU care. And the baby died 4 hours after delivery. On physical examination the infant showed narrow chest, bilateral hypoplastic thumb, fused lower limbs with single foot and 10 toes, absent external genitalia, imperforate anus and umbilical cord with single umbilical artery.
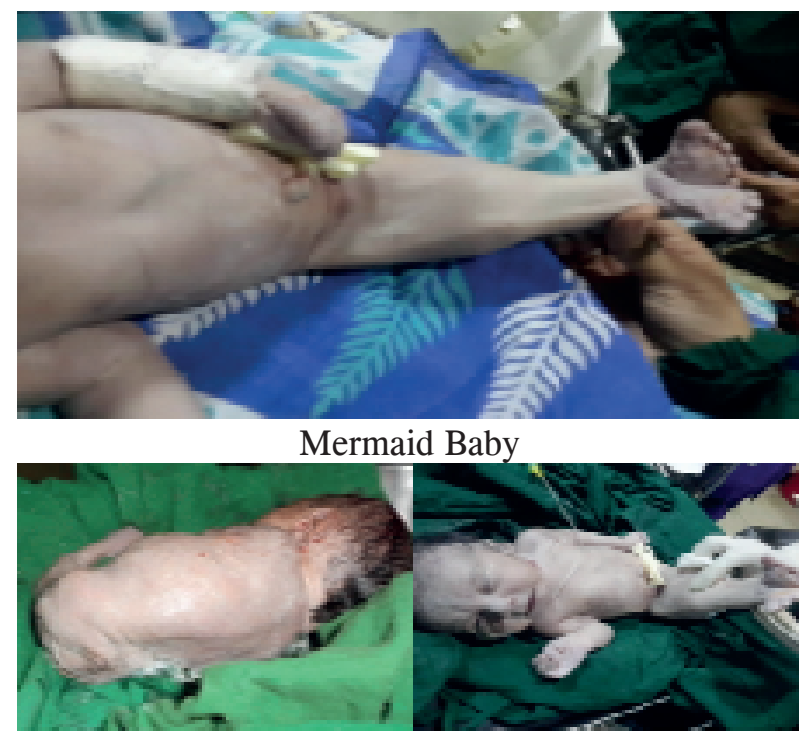

Imperforate anus
There were also prominent epicanthal folds, hyper telorism, downward curved nose, receding chin, low set soft dysplasticears and small slit like mouth suggestive of potters facies. X-ray of lower limbs of the baby showed -completely fused lower limb and one femur and one tibia, incomplete development of pelvis with absent acetabulum, ischium and pubic bones.USG of whole abdomen showed-bilateral agenesis of kidney and urinary bladder. Echocardiography showed-large VSD, ASD.

\section{Discussion}

Various theories have been postulated to explain the etiology of sirenomelia. The first is a "pressure theory" which proposed that some intrauterine force, probably amniotic, acts on the tail of embryo. This leads to defective development of the caudal region including the allantoic structures. Ballantyne ${ }^{4}$ supports this view, noting that the allantois fails to develop completely and that the placenta is vitelline in origin. Bolk ${ }^{6}$ in 1899 proposed a theory of "primary failure". He suggested that sirenomelia resulted from failure of development of the caudal somites leading to greater or lesser hind part deficiency. Weigert coined the theory of "nutritional deficiency". He observed the vitelline nature of the umbilical artery and hypoplasia of the remaining vasculature. In $1961 \mathrm{Duhamel}^{8}$ proposed the theory of "caudal regression" resulting in a spectrum of malformation including anal imperforation and the mermaid syndrome. Sirenomelia is usually fatal within a day or two of birth because of complications associated with abnormal kidney and urinary bladder development and function. In literature approximately 300 cases $^{5}$ are reported worldwide of which 14 are from India. In most of the cases the diagnosis was performed after birth. In antenatal period, sirenomelia can be diagnosed as early as 13 weeks by using high resolution or color Doppler sonography. The condition is usually incompatible with life due visceral abnormalities especially that of renal system. Exceptional cases without renal agenesis have survived, the best example being Tiffany Yorks, a 13-year-old girl who was born with fused legs. Over the years, she has undergone numerous operations to separate her lower extremities ${ }^{6}$. 


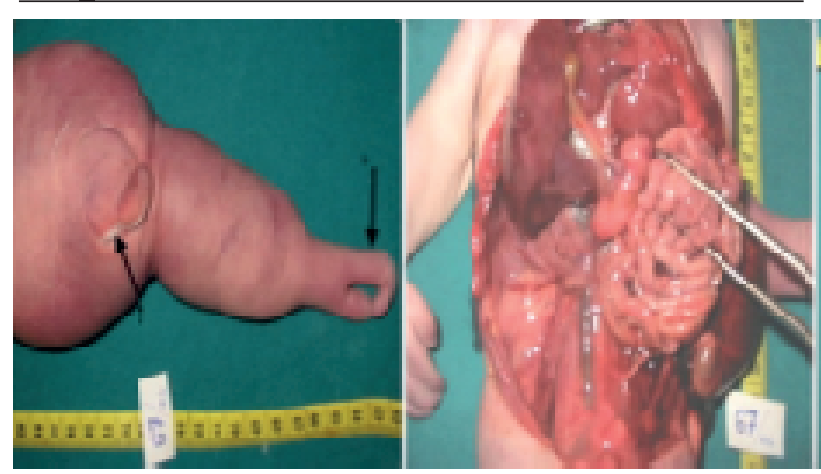

Anal imperforation

Blind bowel
The facial abnormality usually found in sirenomeliac infants known as Potter's facies, which includes large, low-set ears, prominent epicanthic fold, hypertelorism, flat nose and receding chin. In both of our cases, features of Potter's facies were present. When features of Potter's facies are combined with oligamnios and pulmonary hypoplasia it is known as Potter's syndrome which was present in our second case. In our first case, the right thumb was hypoplastic, which was also previously reported. Stocker and Heifetz classified Sirenomeliac infants from Type I to Type VII according to the presence or absence of bones within the lower limb. Although we did not have radiographs to classify our case with certainty, nevertheless based on external examination, we suggest our first and second case belonged to Type IV (partially fused femurs and fused fibula) and Type I (all thigh and leg bones are present) ${ }^{7}$.

Classification of sirenomelia by the presence or absence of bones within the lower limb ${ }^{8}$.
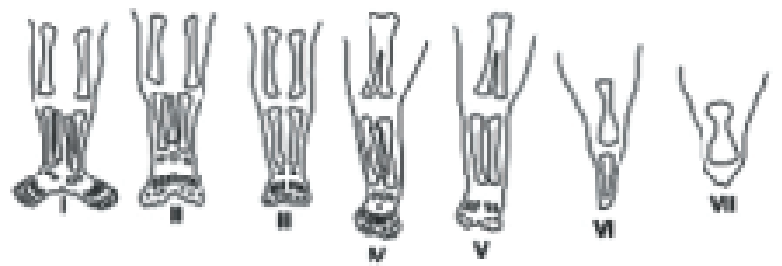

I) all bones of thigh and lower leg present

II) fused fibula

III) fibula absent

IV) partially fused femur, fused fibula

V) partially fused femur

VI) fused femur, fused tibia

VII) fused femur, tibia absent

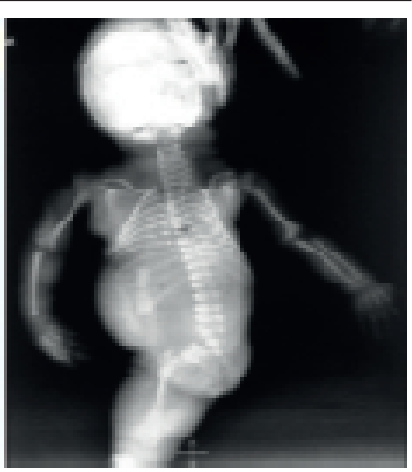

Tubular bladder

$\mathrm{X}$ ray of mermaid

Sirenomelia is fatal in most cases because of the characteristic pulmonary hypoplasia and renal agenesia. About $50 \%$ of the children are born alive after eight or nine months of pregnancy. Death occurs in the five days following birth. Post-natal management requires the presence of kidneys, even if they are dysgenesic ${ }^{9}$. Murphy et alreported one case where a child born with sirenomelia survived; the infant was neurologically normal and had fused lower extremities, an imperforate anus, colon atresia, bilateral fused pelvic kidneys with renal dysplasia and sacral dysplasia, and genital abnormalities. Laparotomy and colostomy were performed, and an eventual separation of the lower extremities was planned. Clarke et al report on a three-month-old infant whose sirenomelia was diagnosed prenatally. The infant was neurologically normal and has fusion of the lower limbs with associated renal dysplasia, an imperforate anus, pelvic and sacral dysplasia, and genital abnormalities. The infant's anomalies are compatible with life and surgical separation of the lower limbs was planned. Managing sirenomelia is difficult and quite costly, requiring several interventions, the results of which are unpredictable (in the case described by Stanton ${ }^{1}$, the patient had five interventions between the age of 15 days and 4 years; she continues to be bedridden and dependent ${ }^{10}$.

Since the prognosis is bad, the management of sirenomelia is difficult, with unpredictable results. It seems more than justified to put the emphasis on antenatal diagnosis in order to choose the cases with better prognosis. Antenatal diagnosis is based on a morphologic ultrasound study (oligohydramnios, bilateral renal agenesis, a single lower limb, a unique umbilical artery, absence of a bladder, undetermined external genitalia, anorectal atresia, 
lumbosacral agenesis). In sirenomelic fetuses, bilateral renal agenesis causes severe oligohydramnios, hindering a reliable sonographic evaluation of the lower extremity in the second and third trimester. In some cases, bilateral renal agenesis is the only sonographic finding 11 . Amnioinfusion and high-frequency transvaginal ultrasonographic probes have proven to be very useful in such a situation Whereas oligohydramnios is a marker of renal agenesis or non-functioning kidneys in the second half of pregnancy, in earlier gestational stages, other contributors to the production of amniotic fluid production are present. Therefore, early in the second trimester, the amount of amniotic fluid should be sufficient to allow detection of sirenomelic abnormalities. Early diagnosis will allow termination of the pregnancy at an early stage, with minor risks and discomfort for the patient ${ }^{12}$.

The MRI (Magnetic Resonance Imaging) permits the evaluation of visceral lesions, avoiding the call for amnioinfusion (which carries a risk of fetal injury, infection, membrane rupture and placental injury) ${ }^{13}$. It seems justifiable to insist on the screening of sirenomelia in diabetic women as well as the screening of diabetes in pregnant women ${ }^{14}$. The therapeutic decision depends on the gestational term at the time of diagnosis, and on the severity of the malformative syndrome and the parents' wish. Genetic counseling should be proposed because of the reoccurrence risks (estimated to be $3 \%-5 \%)^{19}$.

\section{Conclusion}

Sirenomelia is fatal congenital anomaly and has a strong association wirth maternal diabetes. Early diagnosis and termination should be in mind. But 9 mermaid cases survived after reconstructive surgery have been reported. However prevention is possible and should be goal. Regular antenatal check-up with optimum maternal blood glucose level in preconceptional period and in first trimester should be maintained to prevent this anomaly.

\section{Conflict of interest: no}

\section{References}

1. Potter EL (1952). Pathology of the fetus and the newborn. The yearbook publishers, Chicago.
2. Savader SJ, Savader BJ, Clark RA. Sirenomelia without Potter syndrome: MR characteristics. J Comput Assost Tomog 1989; 13: 689-691.

3. Murphy JJ, Fraser GC, Blair GK. Sirenomelia: Case of the surviving mermaid: J Pediatr Surg 1992; 27: 1265-1268.

4. Dareste C. Production artificielle Des. Monstrusites. Paris, 1891, p 420.

5. Ballantyne JW. The occurrence of a nonallantoic or vitelline placeta in the human subject. Trans Edinb Obstet Soc 1898; 23: 54- 81.

6. Bolk L. De sympodie, een voorbeeld von pathologische segmentaal-anatomie. Geneesk BI Klin Lab Prakt 1899; 4: 301-335.

7. Weigert C. Zwei Falle von Missbildung eines Ureter and einer Samenblase mit bemerkungen uber einfache Nabelarterien. Virchows Arch Pathol Anat 1886; 104: 10-20.

8. Duhamel B. From the mermaid to anal imperforation: The syndrome of caudal regression. Arch Dis Child 1961; 36: 152-155.

9. Naveena S, Mrudula C. Sirenomelia- The mermaid syndrome: A case report. IOSR J Dent Med Sci. 2013; 7: 01-4.

10. Vijayaraghavan SB, Amudha AP. High-resolution sonographic diagnosis of sirenomelia. J Ultrasound Med. 2006; 25: 555-7. [PubMed]

11. Sahu L, Singh S, Gandhi G, Agarwal K. Sirenomelia: A case report with literature review. Int $\mathbf{J}$ Reprod Contracept Obstet Gynecol. 2013; 2: 430-2.

12. Shah DS, Tomar G, Preetkiran Sirenomelia. Indian J Radiol Imaging. 2006; 16: 203-4.

13. Dharmraj M, Gaur S. Sirenomelia: A rare case of foetal congenital anomaly. J Clin Neonatol. 2012; 1: 221-3. [PMC free article] [PubMed]

14. Banerjee A, Faridi MM, Banerjee TK, Mandal RN, Aggarwal A. Sirenomelia. Indian J Pediatr. 2003; 70: 589-91. [PubMed]

15. Stocker JT, Heifetz SA. Sirenomelia. A morphological study of 33 cases and review of the literature. Perspect Pediatr Pathol. 1987; 10: 7-50. [PubMed] 